\title{
CUATRO CANTOS-ADIVINANZAS HUITOTO
}

\author{
Jorge Gasché, IIAP/Pbio-Perú ${ }^{1}$
}

\section{RESUMEN}

Cuatro cantos-adivinanzas huitoto son presentados, traducidos, explicados y situados en su contexto ritual de lluaki "fiesta de frutas" y de uuiki "fiesta de la pelota". Las adivinanzas eeiki son un género pragmático de cantos, pues, con ellas, un invitado puede retar al "dueño de la fiesta" y su familia, poniendo a prueba sus conocimientos, pero también se las puede cantar simplemente para divertirse, sin provocar al "dueño". Al explicar la relación entre las palabras de una adivinanza y su solución, descubrimos a los Huitoto como finos y agudos observadores y conocedores de la naturaleza: de las plantas y los animales, sus comportamientos, sus ruidos, sus ritmos biológicos estacionales, su hábitat y su régimen alimenticio. Estos conocimientos, inclusive, pueden interesar y sugerir nuevas hipótesis a los investigadores en ciencias naturales.

PALABRAS CLAVES: Adivinanzas, cantos, huitoto, organización ritual

\section{FOUR WITOTO RIDDLE SONGS}

\begin{abstract}
We present four witoto riddle songs with their translation and interpretation, and we situate them in their ritual context, the fruit festival lluaki and the festival of ball game uuiki. The riddles eeiki are a pragmatic song genus, insomuch as, with them, a invited host can challenge the "owner" of the festival and his family by testing his knowledge, but he can also sing them simply for diversion, without any provocation of the festival owner. When we explain the relations between the words of a riddle and its solution, we discover the Witoto as fine and sharp observers of the nature: the plants, the animals (including insects), their behaviour, their noises, their biological seasonal rhythms, their habitats and their diets. This knowledge can also interest and suggest new hypothesis to researchers in natural sciences.
\end{abstract}

KEYWORDS: Vieldles, songs, ritual organization, witoto

1 Antropologo y [ingüista, investigador del IIAP; jurgas@iquitos.net 
Presentamos, comentamos e interpretamos en este artículo $^{2}$ unos testimonios de la literatura oral del pueblo indígena amazónico Huitoto. Se trata de una clase de cantos que retan la capacidad cognoscitiva, retórica, especulativa - y moral - de un "dueño de fiesta ${ }^{*}$ entre los Huitoto: los cantos-adivinanzas. Los acompañamos de una introducción que los sitúa en el contexto ritual de la sociedad huitoto, que es nuestro interlocutor y terreno de aprendizaje desde más de 30 años. Sin entrar en mayores debates científicos sobre el género discursivo de las adivinanzas y sus propiedades retóricas, nos limitamos a un estudio propiamente etnográfico y esperamos que la materia misma que exponemos ilustre la riqueza de asociaciones metafóricas y metonímicas como nos la revela un pensamiento amerindio, amazónico, no literato, ni esotérico, sino realista, competitivo y operativo en los intercambios materiales y discursivos ceremoniales.

Los Huitoto de la Amazonía colombiana y peruana tienen una clase de danzas cantadas que llaman eeiki, término que los mismos Huitoto traducen por "adivinanza". Mediante este tipo de canto, los bailarines invitados llaman a los "dueños de la fiesta" (rafue naant) - los hombres del patrilinaje de la cabeza de los anfitriones (rafue naama) y sus allegados - a acercarse a su ronda y a adivinar a qué aluden las palabras del canto. Generalmente, los hombres más jóvenes ensayan los primeros a encontrar la solución. Cada vez que fallan, el líder de los cantantes bailarines sigue repitiendo el canto con el coro de sus acompañantes, añadiendo a veces unas palabras para indicar la pista hacia la solución. Pero en última instancia, el reto está planteado al dueño de la fiesta cuyo conocimiento está puesto a prueba y que tiene que comprobar que es un "verdadero padre", por tener el conocimiento adecuado al papel de dueño de la fiesta. Éste, durante la preparación y la celebración de la fiesta, representa el Padre-Creador, el Padre de toda la humanidad, figurada entonces por todos los participantes en la fiesta llamados uruki, - un sustantivo colectivo pariente de urue "niño, niña". El etnógrafo alemán Konrad Theodor Preuss, quien estuvo recolectando la mitología huitoto en Colombia en 1914, también anotó un comentario sobre la fiesta uuikt, "fiesta de la pelota", en la cual se cantan las adivinanzas. Su informante dice lo siguiente sobre la función de ésta y de las adivinanzas:
"Para nosotros la pelota es algo sagrado, es parte de nuestra alma, aunque todo parezca un simple juego. La pelota nos fue entregada en el comienzo (por el padre creador). Gracias a ella vivimos. Si no existiera, la gente estaría triste. Gracias a ella estamos contentos.

Durante la fiesta entonamos (colocamos, planteamos) los cantos eeikt. Son muly largos. Hacemos bailar a nuestros hijos asi como el padre nos enseñó a bailar en el comienzo. Por esta razón, durante la fiesta uuiki se entonan los cantos eeiki. La persona que ofrece la fiesta es aclamada entre la gente. Si todo eso fuera olvidado, la gente estaría triste... Cuando traen uvas caimaronas (Pourouma cecropiaefolia) preguntan por el lugar donde se originó esa fruta y entonan los cantos eeikt. La gente viene a preguntarle al jefe la historia, para tener conocimiento de ella... Si no logra descifrar el canto, la gente se burla de él y dice: "No lo sabe." " ¿Cómo es que no conoce el origen de la pelota y sin embargo organiza esta fiesta?" nos preguntamos. En cambio, si lo descifra, le creemos y estamos contentos..... Cuando el jefe ha descifrado el canto eeiki, el grupo (de cantantes) se va. "El canto que presentaste ha sido descifrado." - "El jefe es un gran sabedor, conoce la historia desde el comienzo, sabe mucho. Por eso organiza la fiesta uuikt. El dueño de esta maloca es un gran sabedor, por eso, él solo entiende el canto eeikt, pues no se cansa."... Los cantos eeiki se entonan siempre en la noche.... Se celebra la fiesta sin disgustos, pues por la noche la gente baila y en el día se distrae jugando a la pelota (Preuss 1994, II: 722-4, 731, 734, 378).

En la fiesta uuiki, los invitados, de día, juegan en el patio delante la "maloca" - la gran casa plurifamiliar con la pelota de caucho, llamada uuikt, tratando de mantenerla en el aire con las rodillas. Esta fiesta es parte de una de las varias "carreras ceremoniales" que distinguen los Huitoto y que se caracterizan por una curva ascendente, luego descendiente, en las prestaciones y cooperaciones ceremoniales, desde el momento en que un joven dueño de fiesta sucede a su padre y empieza con fiestas modestas hasta su fiesta de vejez, cuando, nuevamente, en una fiesta más modesta, trasmite, junto con su carrera, su nombre a su hijo y toma un nombre de viejo, pasando por el punto culminante de la madurez, en la que, gracias a sus numerosos hijos y aliados matrimoniales, es capaz de producir la mayor cantidad de yuca brava, yuca dulce,

2 Agradezco al colega Dr. Juan Álvaro Echeverri de la Universidad Nacional de Colombia su lectura y sus observaciones que me han permitido ajustar unos aspectos de la traducción y de la interpretación. - Este artículo fue redactado en el marco del proyecto "Documentación de las lenguas de la Gente del Centro" ejecutado en un convenio entre el IIAP, la Universidad Ruhr de Bochum, Alemania, y el Instituto Max-Planck para Sicolingüistica en Nimega, Holanda. El proyecto está financiado por la Fundación Volkswagen: Programa DOBES (Documentación de lenguas en peligro). 
coca y tabaco que son los principales bienes con que debe pagar los servicios ceremoniales (cantos, instrumentos musicales, máscaras...) y los frutos, pescados o la carne traida por el gran número de invitados. La fiesta uuiki es celebrada cuando el dueño de la fiesta se encuentra en la cumbre de su carrera. A su inicio, en cambio, las fiestas que organiza se llaman lluaki y son de dimensiones modestas. Actualmente, la fiesta uuiki no se observa más en la práctica. Conocemos a un joven que ha heredado de esta tó, pero nunca hemos asistido a la fiesta de la pelota. En cambio, la fiesta lluaki es de aquellas que se han conservado hasta nuestros dias, precisamente, por tener exigencias modestas y poder ser celebrada por cualquiera que tenga producción hortícola y quiera compartirla en una diversión. Es la que menos prestigio tiene por haber sido entregada al hijo menor del Creador, mientras que las fiestas de la viga de baile (lladiko) y de la morona (o bambú) (sikit) han sido atribuidas al Padre e hijo mayor, respectivamente, al hijo segundogénito, por lo que son las más prestigiosas. Sus atributos son las grandes obras de madera que son, por un lado, la viga de baile (lladiko) de unos 12 metros de largo, cavada para su resonancia y tallada con las figuras de un caimán y de una cara de mujer, $\mathrm{y}$, por el otro, el manguaré (juuat, juuarat) - los dos pesados tambores monóxilos, macho y hembra -. - las dos estatuas de madera (janaraf) del tamaño de una persona, también hombre y mujer, según las variaciones de la carrera de sikii. La pelota uuiki es el atributo más "liviano" de la carrera de este mismo nombre, y su confección exige mucho menos inversión de trabajo y cooperación que las mencionadas grandes obras de madera, cuya elaboración compromete una mano de obra numerosa dentro de relaciones de intercambio de prestaciones ceremoniales complejas.

Las carreras ceremoniales más prestigiosas de lladiko y de sikiti se distinguen de la de lluaki y uuiki por el tipo de intercambio ceremonial. En las fiestas de las primeras, los invitados traen carne fresca o ahumada a la maloca donde se celebra la fiesta; en las fiestas lluaki y uuiki, los invitados traen los frutos que el dueño de la fiesta les ha encargado, acompañados con pescado y, eventualmente - si la suerte les ha hecho encontrar animales en el bosque - carne ahumada. Por eso, la fiesta lluaki es llamada en castellano "fiesta de frutos". En todas las fiestas, el dueño de la fiesta "paga" los aportes de los invitados con productos elaborados de la horticultura: casabe, tamales, mani (Arachis hypogaea), sacha-papa (Dioscorea sp.), piña (Ananas sativa). Caldo de yuca dulce (juiñoi), cahuana (jaigabi), de parte de las mujeres, coca (jïbie) y ampiri (llera), de parte de los hombres, deben ofrecerse a los invitados en abundancia. Todos los productos que ofrece el dueño de la fiesta han sido elaborados por las mujeres y hombres de la maloca (el patrilinaje y sus esposas) y por sus aliados matrimoniales que forman el grupo de los "trabajadores" (nakollae, nakont), a los que el dueño de la fiesta re-distribuye los frutos, los pescados o la carne que ha recibido de los invitados.

K. Th. Preuss ha publicado en su obra sobre la mitología huitoto una serie de cantos adivinanzas en lengua huitoto con traducción, y el Museo etnográfico de Berlín conserva los cilindros de cera grabados por él con esta clase de cantos atribuidos a la fiesta uuikt. Según el informante de Preuss, los clanes donde él investigó y que hablaban el dialecto $m i k a$ en la región nor-occidental del territorio huitoto practicaban un intercambio ceremonial distinto al que observamos entre los clanes de habla minika y buue: "Así que la gente (los invitados) viene a jugar a la pelota y a comer carne" (Preuss 1994, II: 722)." "El jefe recompensa a los grupos que han traído frutos dándoles de comer carne (ibid: 738). Además, entre los "frutos" que los invitados traen y que el informante de Preuss menciona, figuran la "yuca" (Manihot esculenta) (inclusive cocinada y transformada en "tamales"), la "sacha-papa" (Dioscorea sp.), el "dale-dale" (Calathea allouia) - es decir, tubérculos de la chacra - y la caña de azúcar y el plátano (Musa sp.), que en ninguna de las fiestas lluaki a las que hemos asistido fueron entregados al dueño de la fiesta; más bien, la yuca (en forma de casabe o de tamales), la "sacha-papa" y el "dale dale" cocinados eran parte del pago con que el dueño de la fiesta recompensó los frutos recibidos de los invitados.

El autor de estas líneas ha grabado, trascrito y traducido adivinanzas de la fiesta lluaki en 1969/79 y 1973/74 en el río Igaraparaná (Amazonía colombiana), entre los Huitoto que hablan el dialecto minika, $\mathrm{y}$, nuevamente, en 2005 y 2006, con don Alfonso Garcia, el curaca de Pucaurquillo en el río Ampiyacu (Amazonía peruana), que habla el dialecto buue. Las adivinanzas cantadas en coro, desde luego, son cantos de lluaki y de uuiki, es decir, de la fase inicial y de la fase madura de la misma carrera ceremonial. Un género a parte de adivinanzas son los eeikt bitarakt las "adivinanzas 'colocadas', planteadas" o "a propósito del fruto colocado: traído y entregado" ${ }^{43}$, que cantan sólo dos hombres para retar al dueño de la fiesta, que dor huitoto) van en el mismo sentido (ibid.). En el presente estudio, nos limitamos al examen y la interpretación de los eeiki simples, dejando el género del eeikibitaraki para otra oportunidad.

Durante nuestra estadía en el Igaraparaná, 
pudimos asistir a dos fiestas lluaki, en las que ciertos de estos cantos - no todos - fueron presentados como reto al conocimiento del dueño de la fiesta quien respondió con la solución adecuada. En el Ampiyacu, vimos una fiesta lluaki en 2005, pero en ésta las adivinanzas fueron cantadas "por cantar nomás", sin retar al dueño de la fiesta. Con eso constatamos una tendencia al abandono de la función competitiva de estos cantos debido al fallecimiento de los sabedores rituales, los ancianos, y la falta de transmisión de sus conocimientos discursivos a las generaciones más jóvenes.

Los cantos que se cantan y bailan en las fiestas lluaki y uuiki son de cuatro géneros, que se distinguen por su inventario de cantos, de melodías, de pasos de baile y de atuendos rituales. Los invitados que llegan a la fiesta de río abajo cantan cantos muinaki y bailan con un palito largo (radosi, tooirat) en las dos manos; los que vienen de río arriba, muruiki (iduiki, entre los Huitoto del dialecto mika estudiados por Preuss), agitando en sus manos un ramo de helecho (jokome) al ritmo del baile; los del centro Norte del bosque, jaiokt. bailando con una hoja de la palmera chambira (jaioforo, jaiotii), y los del centro Sur del bosque, jimoki vistiéndose con fibras de chambira (jimotii). Cada género usa un dialecto huitoto diferente, con excepción de los jimoki que son cantados en una lengua desconocida e incomprensible que los Huitoto atribuyen a supuestos habitantes antiguos de su región, los Jimuat, que identifican con los Yagua. En los tres primeros géneros existe el sub-género de los cantos adivinanzas. En cuanto a los jimoki, estamos en duda, pues nuestra documentación de este género es muy limitada. Es de notar que, hoy en día, en las fiestas lluaki, los dueños de la fiesta se contentan con invitar socios ceremoniales de río arriba para que canten muruiki y de río abajo para que canten muinaki. Para que los cuatro grupos sean invitados, tendría que ser una fiesta grande con una mayor inversión de bebida, comida, ampiri y coca de lo que suele ocurrir actualmente.

El lenguaje de los cantos difiere del lenguaje cotidiano hablado por usar términos y morfología rituales que "disfrazan", como dicen los Huitoto, el sentido de las palabras y que los conocedores y sabios saben entender. En el presente trabajo presentamos los cantos de cinco maneras. Primero (A.), damos su trascripción en lengua huitoto; luego (B.), anotamos las particularidades lingüisticas rituales y dialectales, dando sus equivalencias en el lenguaje cotidiano y en el dialecto de los comentaristas, el minika. En tercer lugar (C.), presentamos la traducción literal, y en cuarto lugar (D.), la traducción interpretada, que añade entre paréntesis (...) las ideas subyacentes, a las que el canto alude y que se debe sobre-entender si se quiere encontrar la solución de la adivinanza. Finalmente (E.), añadimos una explicación detallada que ubica el sentido del canto en el universo natural, cultural y ritual de la sociedad huitoto.

\section{I.A. Muruiki eeiki}

cantado por Marcelo Diaillarał del clan Aiment "Garza" en el lluaki de Augusto Kuiru, clan Jitomagaro "Sol".

\section{O okollirio o kolliri kolli kolli kollitjaaijaaijaaii \\ O o kollirifuirijeko namaki billari kaimade jakojeko namaki billari kaimade afaijeko namakibillari kaimade \\ Palabras añadidas para facilitar la solución: monifue billari katmade}

Solución: Monifue kallakina abłmameda dukisatbitiïi!

\section{I.B. Notas lingüísticas}

1. Oo kolliri o o kolliri kolli kolli kollitjaaijaaijaaï: Esta línea integra entre palabras onomatopéyicas el nombre del pajarito kolliri, del cual se derivan las sílabas onomatopéyicas kolli kolli kolli. Como se verá también en los ejemplos que siguen, la onomatopeya es constitutiva de todos los cantos y se usa para ritmar la danza. Mis comentaristas indigenas explican: "es pura música".

2. fuirtjeko = fuirtfeko: fuirt-fe-ko: "río abajo-lado declasificador nominal 'forma de bóveda', "maloca en el lado de río abajo"; namaki" "gente".

3. jakojeko $=$ afaijeko $=$ afaifeko "maloca en el lado de río arriba".

4. afaijeko = afaifeko "maloca en el lado de río arriba".

\section{I.C. Traducción literal.}

1 Ookolliri oo kolliritkollikollikollitjaaijaaijaaii

20 o kolliri por venir la gente de la maloca de río

3 Preuss (1921/23) indica, al transcribir y traducir su único ejemplo, bitoraki eeiki traduciendo el término con "colocar las frutas". Su traductora y comentarista, Gabriela Petersen (Preuss 1994, 11: 740) escribe eeiki bitoraki (como nosotros también escuchamos decir a nuestros informantes en el Ampiyacu) y explica: "B̈́taraki se deriva del verbo bitade 'bailar una o dos personas moviéndose en el mismo punto". El sentido más corriente de este verbo, sin embargo, es "colocar", como ella misma lo menciona en su diccionario. Preuss interpretó bita-raki "colocar-fruta"; nosotros nos inclinamos a interpretar bito-ro-ki "colocar-sufjo nominalizador-dasificador nominal (anticipando eei-ki y en concordancia con su sufjo clasificador): "adivinanza de colocación", sea que se "plantee" la adivinanza, sea que la adivinanza se refiera a lo colocado, es decir, el fruto traido. 
3

abajo, está contento

arriba, está contento

4 arriba, está contento

5 Palabras añadidas para facilitar la solución: por venir el alimento, está contento

Solución: Considerándose hormigas "sitaracuy" del alimento, han llegado.

\section{I.D. Traducción interpretada}

1 Ookolliri (canta el pajarito kolliri, que come grillos)

2 Ookolliri por venir (madurando) los (frutos desde) la maloca de río abajo, (el pajarito) está contento

3 por venir (comiendo y espantando grillos) las (hormigas "sitaracuy") de la maloca de río arriba, (el pajarito) está contento

4 por venir las (hormigas "sitaracuy") de la maloca de río arriba, (el pajarito) está contento

5 Palabras añadidas para facilitar la solución: por venir el alimento, (el pajarito y las hormigas "sitaracuy") están contentos

Solución: Considerándose hormigas "sitaracuy" (que comen) alimentos, (los invitados de río arriba) han llegado (a bailary cantar).

\section{E. Explicación}

El canto empieza con una línea onomatopéyica que imita al pajarito kolliri cuando canta por estar contento comiendo grillos. Esta línea que expresa la felicidad ruidosa del pajarito se repite luego con gusto, aliento y energía como refrán, después de cada línea de palabras. La segunda y tercera línea aluden con las palabras "por venir los de la maloca de abajo/arriba" a la razón de la felicidad del pajarito: "los de la maloca de abajo" son los frutos silvestres y sembrados que siempre maduran primero río abajo, luego, poco a poco, vienen madurando hacia río arriba; "los de arriba" son las hormigas "sitaracuy" (Eciton sp.), que forman un denso y largo ejército $y$, en su camino, comen frutos ("umarí [Poraqueiba sericea], "ungurahui" o "milpeso" [Jessenia polycarpa], "aguaje" - "canangucho" [Mauritia flexuosa]), grillos e insectos y toda clase de carne; ellas, desde río arriba, vienen al encuentro de los frutos que maduran desde abajo y espantan en su marcha masiva a los grillos, de manera que el pajarito kolliri encuentra fácilmente su comida, por lo que está contento. De esta manera, el pajarito está asociado a los grillos, que están asociados a las hormigas "sitaracuy", que, a su vez, están asociadas a los frutos maduros, es decir, a un componente de los alimentos (monifue) huitoto y, precisamente, al componente que celebra la fiesta lluakt. Diciendo "los de la maloca de arriba/abajo", el canto humaniza y personaliza a los sitaracuy y los frutos", un procedimiento retórico ritual frecuente, que permite que los cantantes también se refieren a si mismos, pues los cantos muruiki son cantados por los invitados que llegan a la maloca de la fiesta desde río arriba. Son ellos, desde luego, las hormigas "sitaracuy", que vienen desde río arriba al encuentro del alimento, igual contentos como el pajarito kolliri que aprovecha los grillos facilitados por estas mismas hormigas y como las hormigas "sitaracuy" que comen los frutos maduros. Por venir a la fiesta donde abundan la comida y bebida, los cantantes y bailarines se identifican con las "hormigas 'sitaracuy" del alimento", como lo dice el dueño de la fiesta en su respuesta a la adivinanza.

En el caso en que el dueño de la fiesta no encuentra la respuesta correcta después de haber cantado repetidas veces las primeras cuatro líneas, el lider del canto puede añadir las palabras de la quinta línea, que indica que "por venir alimento, (el pajarito o las hormigas) están contentos ${ }^{n 5}$. Con eso, el cantor orienta el pensamiento del adivinador facilitándole las asociaciones necesarias para encontrar la solución. Alimento (de las hormigas) son los frutos que maduran desde río abajo, alimento (del pajarito kolliri)) son los grillos espantados por las hormigas, alimento (frutos) es lo que celebra la fiesta lluakt.

La palabra monifue expresa el concepto general de todo lo que alimenta al Huitoto y que fue creado o instaurado por el Padre Creador para que el ser humano viva; monifue es el bien material que sustenta la vida humana, pero, así como para el ser humano los productos hortícolas y los frutos silvestres (y la carne, en un sentido más amplio) son su monifue, para el pajarito kolliri, el monifue son los grillos, para las hormigas "sitaracuy", el monifue son los frutos silvestres, los grillos y la carne. La canción equipara la noción de "bien existencial primordial del ser humano" y la de "bien existencial primordial de los animales" no de manera metafórica, sino de manera esencialista: todos los seres vivos tenemos nuestro alimento,

4 El bosque es la maloca de los animales y la "madre de monte y de los animales" es su dueño. Eso es parte de la visión huitoto del mundo en la que seres humanos y seres de la naturaleza forman una sola sociedad.

5 En huitoto, la forma verbal de la 3-a persona no indica el número: puede ser singular o plural, según el contexto 
aunque cada especie tenga el suyo y goce de satisfacción y placer con el suyo.

Pero a este conjunto de asociaciones que permiten encontrar la solución de la adivinanza, cabe añadir una idea más que reside en el fondo de la canción y motiva la alegría y la satisfacción que expresa este canto: la idea, no sólo de la felicidad por tener alimento, sino por gozar de abundancia de alimento. En las fiestas huitoto, los anfitriones e invitados acumulan alimento: los primeros, productos de sus chacras, los segundos, frutos asociados a pescado en la fiesta lluaki y uuiki, animales silvestres en las otras carreras. Las fiestas celebran la abundancia de comida que es fruto del trabajo hortícola y de la recolección de frutos, de pesca o de caza. El verbo katmade se refiere a la satisfacción mejor: el gozo y la alegría - debidos a la abundancia de comida de la que disfrutan el pajarito kolliri, las hormigas "sitaracuy" y los bailarines de río arriba que cantan y se identifican con estos últimos. Desde luego, esta adivinanza da voz a un ideal fundamental que sustenta las prácticas festivas huitoto.

\section{II - III.A. Muruiki eeiki}

Cantado por Gabriel Fairiratofe del clan Aiment "Garza" en el lluaki de Augusto Kuiru, clan Jitomagaro "Sol".

1 okuena daiarilli manibuima daiarilli naimanirijai

2 giriüigiriüri lleneji lleneji

3 giriurigiriiri lleneji lleneji

4 ana ille amuillima kudillima noirilli naimanirijai

5 giriurigiriüri lleneji lleneji

6 giriüigiriürilleneji lleneji

7 Invitación a adivinar: Nï̈mookaidi??

8 Respuesta de Abelino Kuiru: Nï ua birui biuaina ittno lloirojijuillana llotio.

9 Rechazo de la respuesta: Na ikino, na ikino.

$10 \mathrm{G}$. Fairiratofe retoma el canto: Fakaitikuesa kakareil11 Repetición del canto....

12 Invitación a adivinar: $\mathrm{JHi}, \mathrm{niH}$ ?

13 Respuesta de Abelino Kuiru: Fimona bailla giririna llollodiuuu!

14 G. Fairiratofe retoma el canto: Fakaitikuesa kakarei!

15 Repetición del canto....

Canto añadido para facilitar la solución:

16 ñugamiñugamiñugamiñugamilleneji lleneji

17 ana ille sotaraima illa jai-ii lleneji lleneji

18 ana ille enuka-kurina raine lleneji lleneji

19 ñugamin ñugamiñugamiñugamilleneji lleneji

20 Invitación a adivinar: Ja kue llogasa.

21 belino Kuiru encuentra la solución: Jidima jigi rïdote llollodiuuu!

22 Aprobación de los cantantes: Jii, jïl!

23 Abelino Kuiru les responde: Buuedi uruiat kaimadotima.

\section{II - III.B. Notas lingüísticas}

1. okuena ... jai: palabras "musicales" a los que los comentaristas no dan significado alguno; daiarilli $=$ daiarilla "brincar repetidas veces" en dialecto buue = tikarilla en dialecto minika; un -a final se convierte a menudo en -i en los cantos; manibuima = manibui "una especie de pájaro"; el sufijo -ma "persona masculina" personifica en el canto al pájaro: "Don Manibui"; naimani "este río grande" en dialecto buue, afemani en dialecto minika. Esta forma del demostrativo indica que el canto es cantado en dialecto buve, cuyos hablantes se sitúan geográficamente río arriba de los hablantes del dialecto minika. Por eso, los cantos en este dialecto son cantados por los bailarines que llegan a la fiesta desde río arriba, aun cuando en su vida diaria hablan el dialecto minika. Saber cantos en un dialecto distinto del diariamente hablado es parte del conocimiento ritual de todos los cantores.

2. girïri: onomatopeya relacionada con el verbo giride "está tronando", pero que puede evocar ruidos de diferentes clases; lleneji: palabra musical que ritma muchos de los cantos de la fiesta lluaki:

4. amuillima $=$ amuilliki "libélula"; el sufijo $-k i$ se remplaza en el canto con el sufijo personificador ma; kudillima $=$ kudi + amuillima "planta que procura un tinte rojo + libélula personificada", de ahí: "libélula roja personificada, Don Libélula-roja"; nooirillt $=$ nooirilla "bañarse repetidas veces" (ver arriba);

16. ñugamí ñugamí ñugamí ñugamì lleneji lleneji: mis comentaristas no supieron dar sentido alguno a la palabra ñugamit, según ellos, es "pura música", y constituye, como las onomatopeyas, la "manteca" (farede) de los cantos, según se expresan los Huitoto para evocar el placer oral que el pronunciar, cantar y ritmar de estas palabras procuran a los cantantes. De la misma naturaleza son la palabra lleneji (ver arriba) y las que se encuentran en las dos líneas siguientes:

17 ... jai-ii llenejilleneji

$18 \ldots$ raine lleneji lleneji, enukakuri = enokakuri: con ese termino ritual se suele nombrar a la vez al pez "fasaco" y al caimán; en un mito huitoto, el sapo korango, parado en la orilla, llama al caimán para que le lleve al otro lado del río: tima enokakurima ruika kue uaibi! "Hermano Don Caimán, ven a 
llevarme al otro lado". "Fasaco" y caimán son ambos carnívoros acuáticos; enokakibe es una hoja que se mezcla con otra especie para producir un tinte negro; jidima, el nombre del "fasaco" en huitoto, contiene la raíz ji- que significa "negro, oscuro", ya que el "fasaco" generalmente se tiene tranquilo en la sombra de la orilla de una quebrada; el nombre "dormilón", que se le da en español colombiano, se refiere a su inmovilidad en la oscuridad de la orilla.

\section{I. - III.C. Traducción literal}

1 okuena brinca el pájaro Don Manibui brinca en el río grandejai

2 girï̈rigirtïrillenejilleneji

3 giritirigirïrillleneji lleneji

4 Don Libélula Don Libélula-roja de abajo en la quebrada se baña en el río grande jai

5 giriziri gitrïri lleneji lleneji

6 giriürigiriiri lleneji lleneji

7 Invitación a adivinar: ¿Dónde está nuestro padre?

8 Respuesta de Abelino Kuiru: Estás avisando la caída de los pijuayitos verdes en esta actual estación.

9 Rechazo de la respuesta: No es, no es.

10 G. Fatriratofe retoma el canto: Pues voy a probar, escucha!

11 Repetición del canto....

12 Invitación a adivinar: Si, dónde?

13 Respuesta de Abelino Kuiru: Estás avisando el ruido del viento del verano.

$14 \mathrm{G}$. Fairiratofe retoma el canto: Pues voy a probar, escucha!

15 Repetición del canto....

Canto añadido para facilitar la solución:

16 ñugamiñugamiñugamiñugamilleneji lleneji

17 abajo en el río está el mordedor jai-ï lleneji lleneji

18 abajo en el río como "enukakuri" raine lleneji lleneji

19 ñugamiñugamin ñugami ñugami lleneji lleneji

20 Invitación a adivinar: Ya pues avisé.

21 Abelino Kuiru encuentra la solución: Estás avisando que el "fasaco" está mezquinando sus huevos.

22 Aprobación de los cantantes: Sii, sii!

23 Abelino Kuiru les responde: Estoy acariciando a mis hijos.

\section{II - III.D. Traducción interpretada}

1 okuena brinca, el pajaro Don Manibui brinca (en la orilla), en el río grande (en la quebrada) jai

2 (se escucha el ruido de la creciente:)girïiri gitriiri Uleneji lleneji

3 girïrigiriiri lleneji lleneji

4 Don Libélula, Don Libélula-roja de abajo en el río se baña, en el río grande (en la quebrada) jai

5 (se escucha el ruido de la creciente:)giriüri giriüri lleneji lleneji

6 giritirigtriürilleneji lleneji

7 Invitación a adivinar: ¿Dónde está nuestro padre (para que venga a adivinar y demostrar su conocimiento)?

8 Respuesta de Abelino Kuiru: Estás avisando la caída de los pijuayitos verdes en esta actual estación.

9 Rechazo de la respuesta: No es, no es.

$10 \mathrm{G}$. Fairiratofe retoma el canto: Pues voy a probar (otra vez), escucha!

11 Repetición del canto....

12 Invitación a adivinar: $\mathrm{Si}$, dónde (está el padre)?

13 Respuesta de Abelino Kuiru: Estás avisando el ruido del viento de este verano.

14 G. Fairiratofe retoma el canto: Pues voy a probar (otra vez), escucha!

15 Repetición del canto....

Canto añadido para facilitar la solución:

16 ñugami ñugamiñugami ñugami lleneji lleneji

17 abajo en el río está el mordedor jai-ii lleneji lleneji

18 abajo en el río (está el mordedor) como "enukakuri" raine lleneji lleneji

19 ñugamt ñugamtñugamiñugamilleneji lleneji

20 Invitación a adivinar: Ya pues avisé.

21 Abelino Kuiru encuentra la solución: Estás avisando que el "fasaco" está mezquinando sus huevos.

22 Aprobación de los cantantes: Sii, sii!

23 Abelino Kuiru les responde: Estoy acariciando a mis hijos (para darles placery alegría).

\section{II - III.E. Explicación}

Se trata de dos cantos adivinanzas que apuntan a la misma solución: el pez llamado "fasaco" (Hoplias malabaricus) en la Amazonía peruana y "dormilón" en la Amazonía colombiana. En el tiempo de la primera creciente del año, cuando hace verano todavía, este pez sube en masa las quebraditas - el canto dice "río grande" para confundir al que adivina - y brinca donde hay palisadas, - como también brincan las libélulas que se bañan botando agua de la superficie del río con su cola encorvada y como brinca el pajarito manibui en la orilla. El ruido de la creciente y de los "fasacos" que suben la quebrada se imita con la onomatopeya girïiri giritiri. El hijo mayor del dueño de la fiesta acepta el reto y se pone a adivinar, pero se equivoca dos veces. Con razón atribuye importancia a la onomatopeya, pues, primero, la asocia al ruido de los embriones verdes de los frutos de la palmera "pijuayo" o "chontaduro" (Bactris gasipaes) que caen al suelo como abortos antes 
que empiece el proceso de maduración de los que se van a poder cosechar, luego, la asocia al ruido del viento que sopla en el verano, la estación en la que se desarrolla la fiesta y que es la que produce la mayor variedad y cantidad de frutos. Abelino sabe que las adivinanzas se refieren a fenómenos que caracterizan los frutos, sus procesos biológicos y sus funciones ecológicas y culturales, así como a fenómenos climáticos estacionales, pero no conoce los sentidos del nombre ritual enokakuri y no toma en cuenta que el canto habla del río (ille, imani), del mundo acuático del pájaro manibui que brinca en las orillas, de la libélula que "se baña" en el agua -, por lo que el ruido también debe de ser asociado a un elemento acuático: el de la creciente en las quebradas y del pez "fasaco" cuando sube las quebradas y brinca en las palisadas. De hecho, los peces y el mundo acuático son otro dominio al que suelen aludir los cantos adivinanzas.

Los peces, en la sociedad huitoto, están asociados a los frutos desde que el mito del origen de la yuca y de todos los frutos comestibles cuenta de un "arbol del saciamiento" (monilla amena) que cargaba todos los frutos, pero que los primeros hombres tumbaron por que se había crecido demasiado alto, volviendo los frutos inaccesibles. Al tumbar los hombres este árbol, las astillas se convirtieron en peces, y el mismo árbol al caer se transformó en la red fluvial, con sus ríos grandes, medianos y afluentes pequeños. Signo de esta asociación entre frutos y peces es también el hecho ritual que, por un lado, el dueño de las fiestas lluakiy uuiki pide a sus invitados qué especie de frutos deben traer a la fiesta, donde se los "pagará" con galletas, "casabe" (taingojit, airiji), ○ envueltos, "tamales" (juart), de yuca, y, por otro lado, los invitados suelen poner sobre sus cargas de frutos unos pescados.

Como los dos primeros ensayos de Abelino fracasan, el cantor añade una segunda canción para ayudarle a encontrar la solución. La palabra clave es, en la línea 17, la palabra sotaraima, el nomen actoris del verbo sotade, que significa "atacar y morder", "dar un mordisco", hablando, por ejemplo, de una serpiente o de una perra que defiende sus crías. El "mordedor", precisamente, es el "fasaco", un pez carnivoro, que ataca con sus mordiscos a quien se le acerca en su tiempo de desove, habiendo subido hacia las cabeceras de las quebradas. "El fasaco está mezquinando, defendiendo sus huevos", dice Abelino con razón. En la línea 18 , se llama a este pez con un nombre "disfrazado", ritual: enokakuri, que no es de conocimiento común, pero con que los discursos rituales se refieren o al "fasaco" o al caimán.

En esta escena ritual del reto que plantea el canto adivinanza y que asume un miembro del grupo de los dueños de la fiesta - en este caso, el hijo mayor del mismo dueño -, nos quedan por evocar unos gestos ceremoniales que acompañan el intercambio de palabras. Cuando se decide a ir a adivinar, Abelino se levanta del patio de la coca (jübibirit), en la periferia de la maloca, donde está reunido su grupo de hombres alrededor de un recipiente con pasta de tabaco diluida con agua (llerabi) y lame este líquido y "mambea" polvo de coca; luego se acerca al círculo de los bailarines llevando una pequeña porción de pasta de tabaco (llera), "ampiri" o "ambil", y, en homenaje al canto y el reto, la entrega al cantante principal antes de pronunciar su propuesta de solución. La pasta de tabaco (mezclada con sal vegetal, faisat) y el polvo de coca son medios de "pago ritual" masculino en la sociedad huitoto.

A su vez, el líder del canto, Gabriel Fairiratofe, al término de su actuación, se va a sentar en la ronda de los dueños de la fiesta, en el patio de la coca, al lado de Abelino, entrega a éste una porción de polvo de coca, envuelta en un pedazo de tejido, y le explica el sentido de todas las palabras de la canción. Abelino comenta: "Así hace la gente que sabe; entrega coca y entrega a otro el sentido de la canción". La transmisión del saber es parte de los intercambios rituales durante la fiesta.

\section{IV.A. Jaioki eeiki}

\section{dictado por Calisto Kuiru}

1 kuvukuvu kuvujijai lleneji jojojïijilleneji lleneji

2 uni aichue uni aichue naimani arife ojere nabena jofo kue mirerillanijojo jijjilleneji

3 kuvukuvu kuvujijai llenejijojojïijilleneji lleneji

\section{IV.B. Notas lingüísticas}

1. La primera línea, como la tercera, es puramente onomatopéyica y musical.

2. aichue = aillue "grande"; la pronunciación $c h$ (oclusiva palatal sorda) en vez de $U$ (oclusiva platal sonora) caracteriza el dialecto de los cantos jaioki; mirerilla en el dialecto del canto = mitaja en el dialecto minika: "tener en la boca (sin morder)"; la terminación -nio -ne es frecuente en ciertas formas verbales del estilo cantado, sin que tenga un valor gramatical definido; ojere significa "manchal o bosque de oje, una planta o un árbol que mis comentaristas no supieron identificar. Lo que los Huitoto siempre tienen en la boca es el polvo de coca, pero mi intérprete no relacionó esta línea con la costumbre de "mambear" coca. 


\section{I.C. Traducción literal}

1 kuvukuvu kuvujijaillenejijojojiijił lleneji lleneji

2 tengo dentro de la boca hoja del manchal de oje del lado de arriba del río grande allá

3 kuvukuvu kuvujijai llenejijojojitij lleneji lleneji

\section{IV.D. Traducción interpretada}

1 kuvukuvu kuvujijai llenejijojo jiiji lleneji lleneji

2 tengo en la boca hoja del manchal de (la planta) oje del lado de arriba (en la cabecera) del río grande, allá

3 kuvukuvu kuvujijaillenejijojoj̈ijł lleneji lleneji

\section{IV.E. Explicación}

Este canto, aun siendo de tamaño muy modesto, nos permite, gracias a los comentarios que hemos recibido durante nuestra anotación y traducción, aclarar un nuevo aspecto de las adivinanzas. $\mathrm{Mi}$ traductor se acordó que tal finado Kueredina Sánchez del clan Aimeni "Garza" había cantado este eeiki en una fiesta a la que trajo pescaditos ahumados de una quebrada a la que había echado barbasco. A ellos se refiere la solución "pesca con barbasco", pues kuvukuvu kuvuji evoca el ruido que hacen los pies cuando remueven el fondo arcilloso de la quebrada para disolver y mezclar la arcilla con el barbasco ya esparcido en el agua y reforzar así su eficiencia. El dueño de la fiesta tiene que tener presente en su memoria qué frutos, qué pescados 0 , eventualmente, qué animal de caza cada bailarín ha traído a la fiesta y le ha entregado, pues, frecuentemente, la adivinanza se refiere de alguna manera a la especie donada por el cantor. Vemos que en este canto, la onomatopeya y la cabecera del río grande son los dos elementos enunciados que, junto con los pescaditos aportados a la fiesta, deben ayudar a los dueños de la fiesta a encontrar la respuesta a la adivinanza. El resto - "tener en la boca la hoja del manchal de oje" - no tiene pertinencia alguna al respecto. Este canto nos ilustra que la relación entre el enunciado y la solución puede ser azarosa y circunstancial. Hay adivinanzas que tienen una respuesta tradicional consagrada, como en los ejemplos I. y II. - III., pero también existe cierta libertad creativa que permite a un cantor asociar palabras de un canto ya conocido a la fruta, el pescado o el animal que él ha traído a la fiesta. El cantor, en todo caso, en la víspera del baile, suele preparar sus turnos de cantos que consisten en $3 \circ 4$ cantos que él va a cantar seguidos, $y$, en este momento, decide qué eeiki va a plantear al dueño de la fiesta y qué cantos (que también podrían eventualmente ser eeiki) va a cantar "para el gusto nomás" (kaimataillena).
Este uso optativo de los cantos nos demuestra que el sub-género eeiki no tiene propiedades formales que lo distinguirían de los cantos lluaki que se cantan sin plantear el reto de la adivinanza, por el sólo placer de cantar y bailar. Lo que de un canto lluaki hace que sea un eeiki es que el cantor utiliza su sentido para aludir a un elemento natural y cultural, vinculado a la celebración de la fiesta lluaki en un sentido amplio, y que, con esta alusión, reta al dueño de la fiesta para que la adivine, la explicite. El sub-género eeiki, desde luego, no es un género formal, sino un género pragmático. Nada impide que, en otra oportunidad, este mismo canto muy breve sea usado, por medio de la parte de la oración que en la situación analizada no tenía pertinencia - "tengo dentro de la boca hoja del manchal de oje" -, para volverse significativa y aludir a otro hecho cultural, tal vez vinculado con la coca, su consumo y sus asociaciones. La variedad de coca llamada kudu jüibie "coca de sambico", por ejemplo, relaciona en su nombre lo que los hombres huitoto siempre llevan en la boca con el universo acuático del pececito "sambico". Pero es eso una especulación nuestra que ningún discurso huitoto nos ha confirmado, que se inspira, sin embargo, en categorías operativas del pensamiento huitoto.

Para significar a los dueños de la fiesta que está cantando un eeiki, el cantor, como hemos visto en el ejemplo II. - III., utiliza una fórmula: “¿Dónde está nuestro padre (entendiendo: para que venga a adivinar y comprobar sus conocimientos de padre de la humanidad)? Pero existen fórmulas más elaboradas de las que pudimos registrar una, que es una conjura o maldición para que el dueño de la fiesta no encuentre la solución. Después de terminar el canto, dice el cantor que plantea la adivinanza, gritando en voz alta:

\section{A. Formula conjuratoria}

pronunciada por Luciano Martínez del clan Jeeiai "Zarigüeya".

1 jisabaikomekinaganomojigidonoite

2 jisabai komeki iri iri duaide

3 okisa oñenito

\section{B. Notas lingüísticas}

1 jisa "hija", pero jisabai se refiere al dueño de la fiesta; komekt "corazón", para los Huitoto el órgano del pensar y sentir; naganomo "en todos los lugares, en todas partes"; jigidonoite = janaïte "se encontrará en dificultad";

2 iri iri duaide fue interpretado de dos maneras: como iridonoite "se enredará y como iri iri doode "dijo "iri 
iri', dijo 'enrédate, enrédate"' en dialecto mika.

3 okisa "icuidado, escucha!"; oñenito = oñeitio "no sacarás, no agarrarás".

\section{Traducción literal}

1 El corazón del dueño de la fiesta se encontrará en dificultad en todas partes.

2 El corazón del dueño de la fiesta se enredará.

3 ¡Cuidado, escucha, no vas a sacar!

\section{Traducción interpretada}

1 ¡El corazón del dueño de la fiesta ha de encontrarse en dificultad en todas las circunstancias!

2 ¡El corazón del dueño de la fiesta ha de enredarse (confundirse)!

3 ¡Cuidado, escucha, no has de sacar (la bolsa de coca que yo daría a quien encuentre la solución de mi adivinanza)!

\section{E. Explicación}

El futuro empleado en las formas verbales de esta fórmula tiene valor desiderativo, respectivamente, prohibitivo (en el caso de la negación): "Ha de ocurrir..., debe ocurrir..., que ocurra..... El cantor conjura la mala suerte deseando que el corazón, la mente del dueño de la fiesta no supere las dificultadas y se quede confundido, y que el dueño de la fiesta no reciba la recompensa: la bolsa de coca que el cantor debe pagarle por la solución de su adivinanza. Fuera de "disfrazar" en el canto, con términos y morfología rituales, los hechos que aluden a la solución de la adivinanza y de establecer lazos sólo tenues entre ésta y las onomatopeyas, el cantor, además, conjura el fracaso del esfuerzo intelectual de los adivinadores con esta fórmula, con la que, al mismo tiempo y precisamente, invita a los dueños de la fiesta a salir al público y a asumir el reto.

Las adivinanzas son un juego social que nos es familiar y que practicamos en un grupo pequeño de personas, amigas o parientes. El que formula la adivinanza establece una relación personal con todos los miembros del grupo que aceptan el reto, escuchando la fórmula, poniéndose a reflexionar y esforzándose a encontrar la solución. Entre los indígenas amazónicos, los Shipibo practican de la misma manera, en grupo pequeño, este juego social, como nos lo ilustran los ejemplos citados por B. Illius (1999: 74-81). Pero, en la medida en que, de sus 6 adivinanzas, las soluciones de 5 consisten en elementos culturales no indígenas (escoba, mosquitero, motor fuera de borda, trapiche, dinero) y una sola en un elemento cultural shipibo (la canoa), es permitido pensar que los Shipibo han adoptado este juego de la sociedad mestiza.

Los cantos-adivinanzas de los Huitoto, que comparten este género pragmático y ceremonial con sus vecinos Ocaina, Nonuya, Muinani y Bora, son parte de un conjunto mayor de relaciones sociales competitivas que las variadas fiestas, que se desarrollan en la realización de las carreras ceremoniales, activan y ponen en escena, dando lugar a provocaciones, agresiones, reclamos, críticas y burlas, pero también a homenajes y alabanzas, a alegría, risa y cortejo. Como arriba lo dijimos, con las adivinanzas, los invitados ponen a prueba públicamente - ante todos los grupos participantes en la fiesta (dueños de la fiesta, trabajadores, invitados) - el conocimiento del dueño del baile y de su grupo, los anfitriones de la fiesta. En los cantos eeiki simples, este conocimiento, más precisamente, consiste en la capacidad de asociar onomatopeyas y ciertas palabras del canto - no todas con frutos, peces, animales, incluyendo insectos, fenómenos climáticos y elementos y gestos culturales. Esta capacidad se apoya eventualmente sobre la memoria del don que el cantor ha entregado (su fruto, su pescado, su carne); recordar este don puede orientar la cadena de asociaciones hacia la buena respuesta.

En nuestro primer ejemplo, la categoría de partida de la especulación adivinadora es la noción de monifue "alimento", que es la fuente de la satisfacción evocada (kaimade) y que el mismo cantor puede nombrar si quiere ayudar a su interlocutor. "Alimento", en la fiesta, siempre está vinculado a "abundancia", causa de alegría y felicidad, que no sólo existen entre los seres humanos - y en particular entre los bailarines que vienen de río arriba para gozar de la fiesta -, sino también entre los otros seres vivos como el pajarito kollirit, que goza de la abundancia de grillos gracias a la marcha masiva de las hormigas "sitaracuy" (kallai), las que comen también los frutos que vienen madurando desde río abajo y que la fiesta lluaki celebra en su intercambio de frutos contra productos elaborados de la chacra.

En el segundo ejemplo, la evocación de una quebrada por medio de un pájaro que frecuenta las orillas, del comportamiento acuático de la libélula y por antífrasis - por medio del "río grande", debe orientar las asociaciones del adivinador para interpretar el significado de la onomatopeya girïri hacia el ruido característico del agua creciente en una quebrada y del pez "fasaco" que sube entonces la quebrada y brinca en las palisadas. La noción de "mordedor", asociada, en el tercer ejemplo, a la 


\section{INSITUTO DE INVESTIGACIONES DE LA $\mid$ FOUIA AMAZONIA PERUANA Amazónico}

evocación de "abajo en el río" y a un nombre ritual que disfraza el nombre del pez en lenguaje ordinario, precisa, más allá del ruido evocado en el canto anterior, el comportamiento agresivo y carnivoro de la especie de pez contemplada por la adivinanza, canalizando las soluciones posibles hacia la única exitosa.

El cuarto ejemplo nos presenta el vínculo más tenue entre el canto y la solución. La sola onomatopeya kuvukuvu kuvuji debería provocar las asociaciones necesarias para llegar a la pesca con barbasco, es decir, entre muchas interpretaciones posibles, al ruido de los pies en el agua cuando diluyen, en el fondo de una quebrada, la arcilla para reforzar la eficiencia del barbasco. Pero, en este caso, la adivinanza se sostiene en el don del cantor-pequeños pescados ahumados-, que son índices de la pesca con barbasco en una quebrada, para orientar la búsqueda del adivinador, a condición - claro está - que éste se recuerde con precisión lo que cada bailarín ha traído a su fiesta. Eso parece en sí un reto a nosotros, que hemos asistido a esta clase de fiestas y a las entradas a menudo masivas de los bailarines, de los que cada uno entrega su don de costumbre envuelto en hoja - a las mujeres de la maloca que los acogen. Sin embargo, el dueño de la fiesta ha asistido, previamente a los cantos adivinanzas, al "pago" que las mujeres hacen de cada don a su dueño $\mathrm{y}$, en ese momento, ha observado lo que cada bailarín ha traído. Cada pago es personal, y el dueño de la fiesta identifica a todos los visitantes con el don que han traído. Hemos observado que, años más tarde, un dueño de baile sigue recordándose qué animal o qué pescado qué persona ha traído a su fiesta celebrada en tal época. El intercambio ritual en las fiestas da la sustancia material a las relaciones sociales personales, que obedecen a una reciprocidad asimétrica debida, obligada, entre el dueño de la fiesta y cada uno de los invitados, y esta sustancia material de las obligaciones mutuas, pero asimétricas, que fundamentan lo que es "sociedad huitoto", se inscribe indeleblemente en la memoria de los actores. De esta misma manera, las adivinanzas cantadas y las respuestas exitosas o erradas encontradas en una fiesta, dan la sustancia de un evento competitivo vivido a las relaciones entre un dueño de fiesta y sus contendores invitados y quedan inscritas en la memoria de los asistentes que han formado el público delante el cual el reto fue planteado y asumido. Así ocurre que los comentaristas huitoto se recuerdan quién ha cantado tal eeiki en el lluaki de tal dueño de fiesta, que encontró tal solución, o, al contrario, por no poder adivinar correctamente, "se enojó" (ikirite), lo que es contrario a la moral de un dueño de fiesta, quien debe aguantar toda provocación con tranquilidad, no rabiar y calmar los ardores agresivos con palabras "frías", pacíficas, convertir el mal en bien mediante la broma, la risa y el gesto generoso.

Las adivinanzas, como vemos, son un reto más allá de la solución intelectual y retórica. Ponen en juego el prestigio del dueño de la fiesta $y$, con eso, su capacidad de soportar un eventual fiasco, de guardar buena postura en condiciones infelices. En un lluaki, me contaron mis comentaristas en el Igaraparaná, un cantor cantó un eeiki en lengua nonuya (hoy en día casi desaparecida), que el dueño del baile no comprendía y para la cual tampoco no disponía de traductor. El cantor, incansablemente repetía su canto por no recibir la respuesta esperada, pero con evidente mala fe, que apuntaba a provocar la ira del dueño de la fiesta. Finalmente lo logró, lo que no hizo más que aumentar la vergüenza que sintieron los participantes en la fiesta por la incapacidad y la debilidad del dueño de la fiesta y despertar sus críticas malévolas.

Sin embargo, tal comportamiento humillador de parte de un invitado es censurado por una regla de buena conducta enunciada por los ancianos que dice que un invitado sólo debería plantear adivinanzas que circulan en los patios de la coca de las malocas relacionadas entre ellas en una misma región por visitas mutuas y conversaciones nocturnas compartidas. No se debería retar a un dueño de baile con adivinanzas importadas de otra región geográfica, donde las palabras sabias que circulan en los patios de las coca son distintas y tienen su propia tradición. Pero, como en todas las sociedades, la buena conducta es una regla que no siempre se respeta, y vemos que la fiesta lluaki, con su posibilidad de retar al dueño de la fiesta, abre un espacio a un invitado que viene a la fiesta con sentimientos hostiles y agresivos hacia el dueño de la fiesta - probablemente por un rencor antiguo -, para que las manifieste públicamente, humillando al dueño de la fiesta y malogrando el ambiente de diversión y alegría, - si el dueño no sabe zafarse de la situación con alguna broma, un chiste $u$ otra provocación de su parte que hace reír a la asistencia. Como reto moral en el manejo de las relaciones sociales y rituales, las adivinanzas huitoto (ocaina, nonuya, muinani y bora) son un hecho retórico "total", que compromete todas las energías físicas (voz, cuerpo, memoria) y sociales (coro y danza, espectadores y oyentes, competición y reto, intercambio ritual) convocadas, organizadas, canalizadas y gastadas ritualmente en la fiesta (rafue), que, para los Huitoto - junto con los Bora, Ocaina, Nonuya, Muinane, Resígaro y Andoke --, es fundadora de su "sociedad", 
FOUA CUATRO CANTOS-ADIMNANZAS

Amazónica HuIToTo

\section{Bibliografía citada}

ILLIUS, BRUNO 1999: Das Shipibo. Texte, Kontexte, Kommentare. Berlin, Dietrich Reimer Verlag.

PREUSS, KONRAD THEODOR 1921/23: Die Religion und Mythologie der Uitoto. Heidelberg, Vandenhoeck \& Ruprecht, J. C. Hinrichs'sche Buchhandlung. 2 Bde. PREUSS, KONRAD THEODOR 1994: Religión y mitología de los Vitotos. Traducción y revisión de la trascripción por Gabriela Petersen de Piñeros, Eudocio Becerra (Bigidima), Ricardo Castañeda Nieto. Bogotá, Editorial de la Universidad Nacional. $2 \mathrm{vol}$ 